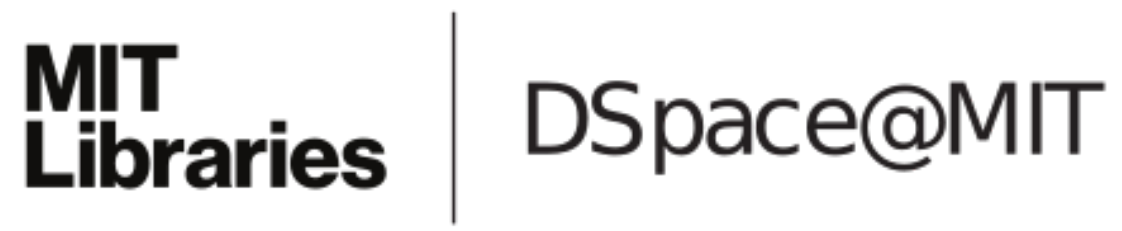

MIT Open Access Articles

Impact of acidic $\mathrm{pH}$ on plant cell wall polysaccharide structure and dynamics: insights into the mechanism of acid growth in plants from solid-state NMR

The MIT Faculty has made this article openly available. Please share how this access benefits you. Your story matters.

As Published: https://doi.org/10.1007/s10570-018-2094-7

Publisher: Springer Netherlands

Persistent URL: https://hdl.handle.net/1721.1/131772

Version: Author's final manuscript: final author's manuscript post peer review, without publisher's formatting or copy editing

Terms of use: Creative Commons Attribution-Noncommercial-Share Alike 


\title{
Impact of Acidic pH on Plant Cell Wall Polysaccharide Structure and Dynamics: Insights into the Mechanism of Acid Growth in Plants From Solid-State NMR
}

\author{
Pyae Phyo ${ }^{1}$, Ying Gu ${ }^{2}$, Mei Hong ${ }^{1 *}$ \\ ${ }^{1}$ Department of Chemistry, Massachusetts Institute of Technology, 170 Albany Street, Cambridge, MA \\ 02139 \\ ${ }^{2}$ Department of Biochemistry and Molecular Biology, Pennsylvania State University, University Park, \\ PA 16802
}

Revised for Cellulose

October 18, 2018

* Corresponding Author: Mei Hong, E-mail: meihong@mit.edu 


\section{Abstract}

Acidification of plant primary cell walls causes cell wall expansion and plant growth. To understand how acidic $\mathrm{pH}$ affects the molecular structure and dynamics of wall polysaccharides, we have now characterized and compared Arabidopsis thaliana primary cell walls in neutral (pH 6.8) and acidic ( $\mathrm{pH} 4.0$ ) conditions using solid-state NMR spectroscopy. Quantitative ${ }^{13} \mathrm{C}$ solid-state NMR spectra indicate that the $\mathrm{pH} 4.0$ cell wall has neutral galacturonic acid (GalA) residues in homogalacturonan $(\mathrm{HG})$ and rhamnogalacturonan $(\mathrm{RG}) \cdot{ }^{13} \mathrm{C}$ INEPT spectra, which selectively detect highly dynamic polymers, indicate that some of the $H G$ and $R G$ chains in the interfibrillar region have become more dynamic in the acidic wall compared to the neutral cell wall, whereas other chains have become more rigid. Consistent with this increased dynamic heterogeneity, $\mathrm{C}-\mathrm{H}$ dipolar couplings and $2 \mathrm{D}{ }^{13} \mathrm{C}-{ }^{13} \mathrm{C}$ correlation spectra indicate that some of the $\mathrm{HG}$ backbones are partially aggregated in the acidic cell wall. Moreover, 2D correlation spectra measured with long mixing times indicate that the acidic cell wall has weaker cellulose-pectin interactions, and water-polysaccharide ${ }^{1} \mathrm{H}$ spin diffusion data show that cellulose microfibrils are better hydrated at low $\mathrm{pH}$. Taken together, these results indicate a cascade of chemical and conformational changes of wall polysaccharides due to wall acidification. These changes start with neutralization of the pectic polysaccharides, which disrupts calcium crosslinking of $\mathrm{HG}$, causes partial aggregation of the interfibrillar $\mathrm{HG}$, weakens cellulose-pectin interactions, and increases the hydration of both cellulose microfibrils and matrix polysaccharides. These molecular-level structural and dynamical changes are expected to facilitate polysaccharide slippage, which underlies cell wall loosening and expansion, and may occur both independent of and as a consequence of protein-mediated wall loosening.

Keywords: plant cell wall, solid-state NMR, acidic $\mathrm{pH}$, acid growth, cellulose-pectin interaction

\section{Abbreviations:}

Ara, A, arabinose; CW, cell wall; CP, cross polarization; DP, direct polarization; Gal, Galactose; GalA, GA, galacturonic acid; HG, homogalacturonan; INEPT, insensitive nuclei enhanced by polarization transfer; i, Interior crystalline cellulose; MAS, magic-angle spinning; PDSD, proton-driven ${ }^{13} \mathrm{C}-{ }^{13} \mathrm{C}$ spin diffusion, RG-I, rhamnogalacturonan I; Rha, R; rhamnose; SSNMR, solid-state nuclear magnetic resonance; s, surface amorphous cellulose; XyG, xyloglucan; Xyl, x, xylose. 


\section{Introduction}

The primary cell wall of growing plants possesses a complex and interconnected polysaccharide network to provide both mechanical strength and flexibility to the cell. The mechanical strength allows plant cell walls to withstand tensile and compressive forces while the flexibility allows the cell wall to expand to permit plant tissue growth (Cosgrove 2018). In growing plants, the polysaccharide network is altered by a number of environmental factors and wall-modifying agents to loosen the cell wall. Among these, the best-known trigger for wall loosening and extension is auxin-induced acidification. The acid growth theory, introduced five decades ago (Arsuffi and Braybrook 2018; Hager et al. 1971; Majda and Robert 2018), states that the hormone auxin activates plasma-membrane $\mathrm{H}^{+}$-ATPase proton pumps to acidify the extracellular or apoplastic $\mathrm{pH}$, which in turn activates wall-loosening enzymes as well as increasing the intracellular turgor pressure to allow cell elongation. The apoplastic $\mathrm{pH}$ is normally about 6, but auxin treatment decreases it to 4.5-5.0. When neutral or basic buffer is introduced, cell expansion subsides (Hager et al. 1971; Tepfer and Cleland 1979). At the end of cell growth, calcium channels are activated to increase the calcium ion concentration in the cytosol, which inhibits the $\mathrm{H}^{+}$-ATPase activity, which in turn raises the apoplastic $\mathrm{pH}$, halting wall expansion (Majda and Robert 2018).

While acid growth of plants is triggered by auxin in vivo, research on many plant species in the last few decades have shown that acidic $\mathrm{pH}$, in the absence of the hormone itself, already causes wall extension (Hager 2003). When the primary cell wall is clamped to a constant-force extensometer, the wall is found to extend readily in acidic buffer, in the absence of auxin, while almost no extension is found at neutral pH (Cosgrove 2000; Durachko and Cosgrove 2009; Ezaki et al. 2005). Interestingly, wall extension in tissues such as coleoptile or hypocotyl is inhibited by $\mathrm{Cu}^{2+}, \mathrm{Co}^{2+}$, and $\mathrm{Mn}^{2+}$, which inhibit enzymatic processes, indicating the involvement of proteins in acid growth (Hager 2003; Hager et al. 1971; Prat et al. 1984; Tepfer and Cleland 1979). A number of proteins and enzymes have been identified to be involved in acid growth (Hager 2003; Laskowski et al. 2006). For example, the wallloosening protein, expansin, is activated by wall acidification and exhibits optimal activity at $\mathrm{pH} 4$ (Cosgrove 2000; Cosgrove 2005; Cosgrove et al. 1997; Durachko and Cosgrove 2009). Exogenous auxin treatment induces the expression of various genes, including those encoding for pectin methylesterases (PMEs) and pectate lyases in Arabidopsis roots (Laskowski et al. 2006). PME activity cleaves methyl-esters from HG, which were shown by AFM indentation data to cause tissue softening prior to cell wall expansion (Braybrook and Peaucelle 2013). When de-methyl-esterification is inhibited, pectin lyases can no longer degrade pectins, which correlates with reduced wall loosening. These data suggest that acidic $\mathrm{pH}$ causes wall loosening by inducing protein and enzyme processes that eventually change the pectin structural network.

However, this protein-centric view of acid growth does not explain the fact that auxin-induced plant growth starts rapidly, within minutes, well before transcriptional changes that activate wallloosening proteins (Cosgrove 2000; Lüthen et al. 1990; Mcqueen-mason and Cosgrove 1995). To answer the question of whether acid growth of plant cells has a protein-independent mechanism, it is instructive to consider the recent increasing body of molecular-level structural and dynamical information about plant cell wall polysaccharides obtained from solid-state NMR (Dick-Perez et al. 2011; Wang and Hong 2016; Wang et al. 2015; Wang et al. 2012). ${ }^{13} \mathrm{C}$ NMR spectra of ${ }^{13} \mathrm{C}$-enriched primary cell walls of Arabidopsis (Dick-Perez et al. 2011), Brachypodium (Wang et al. 2014), and Zea Mays (Wang et al. 2016a) provided detailed and multifaceted evidence that pectin interaction with cellulose and pectin dynamics in the interfibrillar space are important for wall mechanics. For example, ${ }^{13} \mathrm{C}$ spectra of the cell walls of a fast-growing Arabidopsis mutant (Phyo et al. 2017b) and rapidly elongating Arabidopsis inflorescence stem (Phyo et al. 2017a) show weaker pectin-cellulose through-space cross peaks, increased methyl esterification levels, and reduced homogalacturonan $(\mathrm{HG})$ crosslinking compared to their respective slower growing counterparts. The NMR spectra of inflorescence primary cell wall also show higher pectin concentrations, increased RG-I sidechain branching, larger pectin mobility, and higher pectin hydration. For never-dried primary cell walls of two-week-old Arabidopsis 
seedlings, pectin-cellulose cross peaks are observed in $2 \mathrm{D}{ }^{13} \mathrm{C}-{ }^{13} \mathrm{C}$ correlation spectra (Wang et al. 2015), and water accessibility of cellulose lags behind the hydration of pectins (White et al. 2014), indicating that the cellulose surface is covered by pectins. Together, these solid-state NMR data point to pectin-cellulose interactions as an essential feature of mature primary cell walls, which need to be weakened in order to allow wall expansion, and indicate that reduced pectin crosslinking and higher esterification correlate with wall loosening.

Given these observations of pectins' role in primary cell wall mechanics, here we investigate how acidic $\mathrm{pH}$ changes the structure and dynamics of wall polysaccharides, in the absence of protein and enzyme actions. We treated the Arabidopsis primary cell wall to a $\mathrm{pH} 4$ buffer, and compared its ${ }^{13} \mathrm{C}$ NMR spectra with those of neutral-pH cell wall. The ${ }^{13} \mathrm{C}$ solid-state NMR spectra give a wealth of information about $\mathrm{pH}$-induced differences in polysaccharide chemical structure, molecular mobility, hydration, and intermolecular interactions. The NMR data indicate that wall acidification to $\mathrm{pH} 4$ quantitatively neutralizes all galacturonic acid residues in HG and RG-I, which profoundly changes the structure and dynamics of the polysaccharide network. The pectins become partially separated from cellulose microfibrils, as manifested in $2 \mathrm{D}{ }^{13} \mathrm{C}-{ }^{13} \mathrm{C}$ correlation spectra. Pectins are partially aggregated, as shown by measured ${ }^{13} \mathrm{C}-{ }^{1} \mathrm{H}$ dipolar couplings, consistent with the loss of the calcium-crosslinked HG network. ${ }^{1} \mathrm{H}$ spin diffusion data from water to polysaccharides indicate increased hydration of cellulose microfibrils, consistent with reduced interaction between cellulose and matrix polysaccharides. These data indicate that acidic $\mathrm{pH}$ disrupts the cellulose-pectin interaction and pectin-pectin interaction, thus allowing the necessary polymer slippage that underlies wall loosening.

\section{Material and Methods}

\section{Growth of uniformly ${ }^{13} \mathrm{C}$-labeled Arabidopsis primary cell walls}

Arabidopsis thaliana primary cell walls were prepared and ${ }^{13} \mathrm{C}$ labeled as previously described (White et al. 2014). Seedlings were grown in the dark for 10 days in $2.2 \mathrm{~g} / \mathrm{L}$ Murashige and Skoog (MS) liquid culture containing $0.5 \%{ }^{13} \mathrm{C}$-labeled glucose as the sole carbon source. The harvested seedlings were ground into fine powder in liquid nitrogen, and washed with $1.5 \%(\mathrm{w} / \mathrm{v})$ SDS for $3 \mathrm{~h}$ to solubilize cell membranes and proteins and inactivate endogenous wall-degrading enzymes. The material was washed with water, incubated with $\alpha$-amylase $(5,000$ units per $30 \mathrm{~mL})$ from porcine pancreas (SigmaAldrich) in sodium MES buffer at $\mathrm{pH} 6.8$ to remove starch, then washed with $1.5 \%(\mathrm{w} / \mathrm{v})$ SDS overnight. Wall materials were exchanged in $\mathrm{dd}_{2} \mathrm{O}$ at $\mathrm{pH} 6.8$ and $\mathrm{pH} 410$ times before the final wash containing $2 \mathrm{mM} \mathrm{NaN}_{3}$ at $\mathrm{pH} 6.8$ and $\mathrm{pH} 4$. A total of $0.02 \%(\mathrm{w} / \mathrm{v}) \mathrm{NaN}_{3}$ was used in all solutions to inhibit microbial growth. The samples were centrifuged to remove bulk water.

\section{Solid-state NMR spectroscopy}

All SSNMR spectra were measured on an $800 \mathrm{MHz}$ (18.8 T) Bruker Advance II spectrometer and a $600 \mathrm{MHz}(14.1 \mathrm{~T}$ ) Bruker Advance II HD spectrometer using $3.2 \mathrm{~mm}$ magic-angle-spinning (MAS) probes. Typical radiofrequency field strengths were $40-62.5 \mathrm{kHz}$ for ${ }^{13} \mathrm{C}$ and $50-83 \mathrm{kHz}$ for ${ }^{1} \mathrm{H}$. TPPM decoupling was applied during acquisition. All ${ }^{13} \mathrm{C}$ chemical shifts were externally referenced to the adamantane $\mathrm{CH}_{2}$ peak at 38.48 ppm on the tetramethylsilane (TMS) scale.

$1 \mathrm{D}{ }^{13} \mathrm{C}$ MAS spectra were measured at $296 \mathrm{~K}$ under $10 \mathrm{kHz}$ MAS on the $800 \mathrm{MHz}$ NMR using ${ }^{1} \mathrm{H}-{ }^{13} \mathrm{C}$ cross polarization $(\mathrm{CP})$ or ${ }^{13} \mathrm{C}$ direct polarization (DP) to generate the initial ${ }^{13} \mathrm{C}$ magnetization. Quantitative ${ }^{13} \mathrm{C}$ DP spectra were measured using a recycle delay of $30 \mathrm{~s} .{ }^{13} \mathrm{C} \mathrm{CP}$ spectra were measured using a contact time of $500 \mu \mathrm{s}$ and a recycle delay of $2 \mathrm{~s}$. Refocused INEPT (Elena et al. 2005) spectra were measured using a recycle delay of $2 \mathrm{~s}$ and a total ${ }^{1} \mathrm{H}-{ }^{13} \mathrm{C}$ polarization transfer period of $6 \mathrm{~ms}$, which comprises of two delays of $1.8 \mathrm{~ms}$ followed by two delays of $1.2 \mathrm{~ms}$. These delays correspond to $1 /\left(4 \mathrm{~J}_{\mathrm{CH}}\right)$ and $1 /\left(6 \mathrm{~J}_{\mathrm{CH}}\right)$, respectively, calculated based on the ${ }^{13} \mathrm{C}-{ }^{1} \mathrm{H} \mathrm{J}$-coupling of $140 \mathrm{~Hz}$ (Phyo et al. 2017a; Yu et al. 2012). 
2D ${ }^{13} \mathrm{C}-{ }^{13} \mathrm{C}$ J-INADEQUATE spectra (Cadars et al. 2007; Lesage et al. 1997) correlating doublequantum and single-quantum ${ }^{13} \mathrm{C}$ chemical shifts were measured for resonance assignment of matrix polysaccharides. The experiments were carried out on the $800 \mathrm{MHz} N M R$ at $296 \mathrm{~K}$ under $12 \mathrm{kHz} \mathrm{MAS}$. The experiment starts with ${ }^{13} \mathrm{C}$ DP with a recycle delay of $2 \mathrm{~s}$. The spectral widths were $333 \mathrm{ppm}(67$ $\mathrm{kHz})$ and $83 \mathrm{ppm}(17 \mathrm{kHz})$ for the direct and indirect dimensions, respectively. 320 increments were used for the indirect dimension. 128 and 112 scans were co-added for the $\mathrm{pH} 6.8$ and $\mathrm{pH} 4.0$ samples, respectively.

Two sets of $2 \mathrm{D}$ proton-driven ${ }^{13} \mathrm{C}-{ }^{13} \mathrm{C}$ spin diffusion (PDSD) spectra were measured at $296 \mathrm{~K}$ and $255 \mathrm{~K}$. The high-temperature spectra were measured at $800 \mathrm{MHz}$ under $10 \mathrm{kHz} \mathrm{MAS}$ using a 30 ms mixing time, $1.9 \mathrm{~s}$ recycle delay, and $1 \mathrm{~ms} \mathrm{CP}$ contact time. This experiment detects primarily intramolecular cross peaks. The spectral widths were $249 \mathrm{ppm}(50 \mathrm{kHz})$ and $124 \mathrm{ppm}(25 \mathrm{kHz})$ for the direct and indirect dimensions, respectively. $t_{1}$ increments of 400 were used in the indirect dimension, and 96 scans and 64 scans were acquired for the $\mathrm{pH} 4.0$ and $\mathrm{pH} 6.8$ samples, respectively. The lowtemperature 2D PDSD spectra were measured at $600 \mathrm{MHz}$ under $10 \mathrm{kHz}$ MAS using a mixing time of $1.5 \mathrm{~s}$, a $1.3 \mathrm{~s}$ recycle delay, and a CP contact time of $500 \mu \mathrm{s}$. This experiment detects long-range intermolecular cross peaks under conditions where the matrix polysaccharides are largely immobilized. The spectral widths were $331 \mathrm{ppm}(50 \mathrm{kHz})$ and $110 \mathrm{ppm}(17 \mathrm{kHz})$ for the direct and indirect dimensions, respectively. $t_{1}$ increments of 140 and 160 were used in the indirect dimension and 544 scans and 480 scans were acquired for $\mathrm{pH} 4.0$ and pH 6.8 samples, respectively.

${ }^{13} \mathrm{C}$-detected water-polysaccharide ${ }^{1} \mathrm{H}$ spin diffusion experiments (White et al. 2014) were conducted to investigate water-polysaccharides interactions. The spectra were measured under $10 \mathrm{kHz}$ MAS at $\sim 253 \mathrm{~K}$ to minimize chemical exchange, whose rates differ between neutral and acidic $\mathrm{pH}$ (Liepinsh and Otting 1996). A ${ }^{1} \mathrm{H} \mathrm{T}_{2}$ filter was used to suppress the polysaccharide ${ }^{1} \mathrm{H}$ magnetization while retaining $40-60 \%$ of the water magnetization. The filter time was $250 \mu$ s and $500 \mu$ s for the $\mathrm{pH} 6.8$ and $\mathrm{pH} 4.0$ samples. ${ }^{1}{ }^{1} \mathrm{H}$ spin diffusion mixing period of $0-32 \mathrm{~ms}$ was then applied to allow waterpolysaccharide polarization transfer, after which a ${ }^{1} \mathrm{H}-{ }^{13} \mathrm{C} \mathrm{CP}$ contact time of 500 us allows ${ }^{13} \mathrm{C}$ detection of the transferred polysaccharide magnetization.

${ }^{13} \mathrm{C}-{ }^{1} \mathrm{H}$ dipolar chemical-shift (DIPSHIFT) correlation experiments were carried out on the 800 $\mathrm{MHz} \mathrm{NMR}$ at $296 \mathrm{~K}$ to measure polysaccharide mobility (Munowitz et al. 1981). The initial ${ }^{13} \mathrm{C}$ magnetizations were created using either CP or DP. The DP-DIPSHIFT experiment was conducted under $7.6 \mathrm{kHz}$ MAS with a recycle delay of $20 \mathrm{~s}$ to obtain quantitative intensities that reflect the motional amplitudes of all wall polysaccharides. The CP-DIPSHIFT experiment preferentially detects the mobility of more rigid polysaccharides. The coupling was measured in a doubled fashion by fixing the ${ }^{1} \mathrm{H}$ homonuclear decoupling period to one rotor period while shifting the ${ }^{13} \mathrm{C} 180^{\circ}$ pulse during the rotor period (Hong et al. 1997). The CP-DIPSHIFT experiment was conducted under $9.6 \mathrm{kHz}$ using a 2$\mathrm{s}$ recycle delay and a $500-\mu$ s contact time. ${ }^{1} \mathrm{H}$ homonuclear decoupling was achieved using the FSLG pulse sequence (Bielecki et al. 1989) with a ${ }^{1} \mathrm{H}$ transverse field strength of $83 \mathrm{kHz}$. The theoretical scaling factor of 0.577 was verified using the model peptide formyl-Met-Leu-Phe-OH (Rienstra et al. 2002). The measured couplings were divided by the rigid-limit values, which are $13.1 \mathrm{kHz}$ and $26.2 \mathrm{kHz}$ for the single and doubled-DIPSHIFT experiments to obtain the $\mathrm{C}-\mathrm{H}$ bond order parameter, $\mathrm{S}_{\mathrm{CH}}$.

\section{Results}

Quantitative ${ }^{13} \mathrm{C}$ NMR spectra report the effects of $\mathrm{pH}$ on the polysaccharide chemical structure

The two Arabidopsis primary cell wall samples used in this study were dark-grown under identical conditions but were subjected to different $\mathrm{pH}, \mathrm{pH} 6.8$ and $\mathrm{pH} 4.0$, after harvesting. Thus, we expect the polysaccharide chain composition to be unaffected but the $\mathrm{COO}^{-}$bearing galacturonic acid (GalA) residues, whose bulk $\mathrm{pK}_{a}$ is $\sim 3.5$ (Kohn and Kovac 1978; White et al. 2014), to be altered. Quantitative ${ }^{13} \mathrm{C}$ NMR spectra (Fig. 1A) bear out this hypothesis. These spectra were measured using 
a recycle delay of $30 \mathrm{~s}$, which is 5-10 times that of the ${ }^{13} \mathrm{C} \mathrm{T}_{1}$ relaxation times of $0.3-5 \mathrm{~s}$ (Hediger et al. 1999; Wang et al. 2015; Wang et al. 2014) for these uniformly ${ }^{13} \mathrm{C}$-labeled Arabidopsis cell walls. Direct ${ }^{13} \mathrm{C}$ excitation and the long recycle delays together ensure that the relative peak intensities in the spectra quantitatively reflect the relative concentration of each polysaccharide, regardless of their mobility and the number of protons bonded to each carbon. The two cell walls exhibit similar ${ }^{13} \mathrm{C}$ chemical shifts and linewidths, except for the 170-180 ppm, 99-101 ppm, 78-80 ppm, 68-70 ppm regions. In the carbonyl region, the high-pH samples exhibits three signals, which have been previously assigned to negatively charged $\mathrm{COO}^{-}(176 \mathrm{ppm})$, acetyl $\left(\mathrm{OCOCH}_{3}, 174 \mathrm{ppm}\right)$, and methyl ester $\left(\underline{\mathrm{COOCH}_{3}}, 172 \mathrm{ppm}\right.$ ) (Phyo et al. 2017b). Wall acidification completely removed the 176-ppm $\mathrm{COO}^{-}$ peak, indicating quantitative protonation of GalA residues at $\mathrm{pH}$ 4. Concomitantly, the 174-ppm peak increased in intensity in the low-pH spectrum, consistent with the formation of new $\mathrm{COOH}$ groups. In the 100-ppm region, the low-pH spectrum shows a weaker 99.8-ppm peak, part of which results from GalAC1 of negatively charged HG (Phyo et al. 2017b), consistent with charge neutralization of GalA. The residual 99.8-ppm intensity can be assigned to xylose C1 (x), methyl-esterified GalA C1 and rhamnose (Rha) C1 based on 2D J-INADEQUATE spectra of the present sample as well as previously measured primary wall samples (see Fig. 2 below) (Phyo et al. 2017a; Phyo et al. 2017b). The acidic cell wall also exhibits a higher 101-ppm peak, which is most likely due to a downfield shift of the neutralized GalA residues from $99.8 \mathrm{ppm}$. In comparison, the $\mathrm{pH}$ change did not affect the intensities of the 172-ppm and 53-ppm peaks of methyl esters and the 21-ppm peak of acetyl $\mathrm{OCO}_{\mathrm{CH}}$, indicating that acetylation and esterification are unaffected by $\mathrm{pH}$ change.
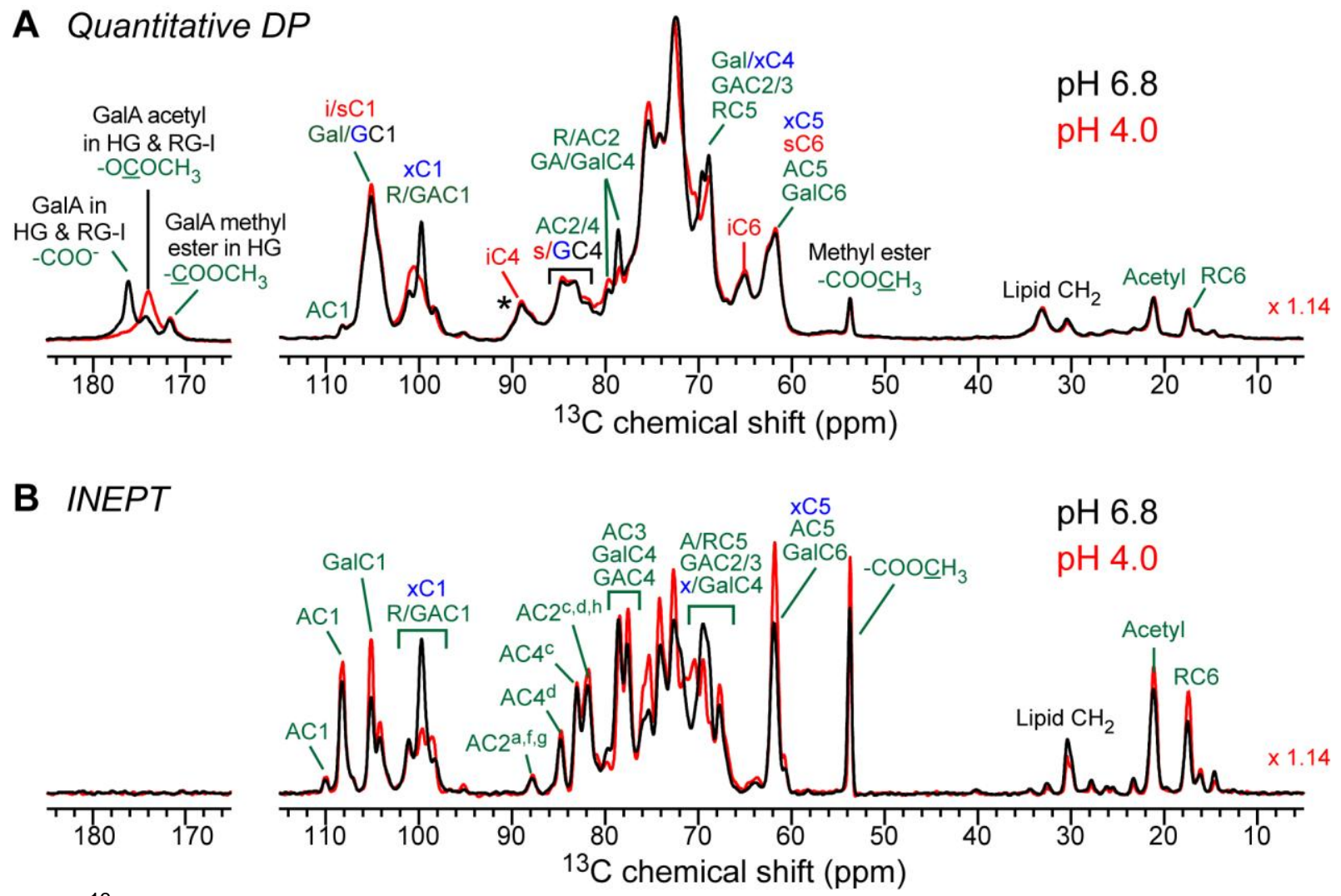

Figure 1. ${ }^{13} \mathrm{C}$ NMR spectra of Arabidopsis primary cell walls at $\mathrm{pH} 6.8$ and $\mathrm{pH} 4.0$. (A) Quantitative ${ }^{13} \mathrm{C}$ spectra measured with a recycle delay of $30 \mathrm{~s}$. A scaling factor of 1.14 was applied to the $\mathrm{pH} 4.0$ spectrum to account for mass difference between the two samples, and is determined from the ratio of the integrated areas of the high-pH spectrum to that of the low-pH spectrum, excluding the 25-30 ppm lipid region. The $\mathrm{pH} 4.0$ spectrum lost the 176-ppm $\mathrm{COO}^{-}$peak, indicating protonation and 
neutralization of GalA residues. (B) ${ }^{13} \mathrm{C}$ INEPT spectra of highly dynamic polysaccharides. A scaling factor of 1.14 was applied to the $\mathrm{pH} 4.0$ spectrum. The low-pH spectrum shows higher intensities than the high-pH spectrum for most pectin signals such as Rha C6, Ara C1, Gal C1, and acetyl in RG-I.

Apart from the acid-induced neutralization of the GalA residues, the 108-ppm arabinose (Ara) C1, the 98.2-ppm C1 peak of type-i GalA, and the 17-ppm Rha C6 signal remain the same, and the cellulose intensities at $89 \mathrm{ppm}, 84 \mathrm{ppm}, 65 \mathrm{ppm}$ and $62 \mathrm{ppm}$ are also unchanged. Therefore, wall acidification specifically neutralizes the GalA residues in HG and RG-I, without affecting the concentrations and chemical structures of cellulose, hemicellulose, and pectin sidechains in the wall.

\section{Matrix polysaccharide mobilities from INEPT ${ }^{13} \mathrm{C}$ spectra}

To investigate whether wall acidification affects the dynamics of matrix polysaccharides, we measured the $1{ }^{13} \mathrm{C}$ INEPT (Insensitive Nuclei Enhanced by Polarization Transfer) spectra (Fig. 1B), which preferentially detect highly mobile molecules with vanishing ${ }^{1} \mathrm{H}-{ }^{1} \mathrm{H}$ dipolar couplings under moderate MAS (Elena et al. 2005). The intensities of the INEPT spectra relative to the quantitative spectra indicate that less than $\sim 10 \%$ of all matrix polysaccharides are detected. These matrix polysaccharides are most likely located in the interfibrillar region, well separated from cellulose microfibrils. The INEPT-detected ${ }^{13} \mathrm{C}$ spectra show similar linewidths for the $\mathrm{pH} 6.8$ and $\mathrm{pH} 4.0$ cell walls but different intensities at a number of ${ }^{13} \mathrm{C}$ chemical shifts. The low-pH cell wall exhibits higher intensities for the 16- and 17-ppm Rha C6 signals, the 21-ppm acetyl signal, the 54-ppm methyl ester peak, the 105-ppm galactose C1 (Gal) peak, and the 108-ppm Ara C1 peak. Several overlapped matrix polysaccharide peaks (62 ppm, $67.8 \mathrm{ppm}, 75.5 \mathrm{ppm}, 77 \mathrm{ppm}$, and $78.6 \mathrm{ppm}$ ) are also stronger in the low-pH spectrum (Phyo et al. 2017a; Phyo et al. 2017b). Thus, the majority of RG-I backbone, methylated $H G$, and the galactan and arabinan sidechains of RG-I are more dynamic in the low-pH cell wall. In comparison, the 101-ppm xyl/GalA/Rha C1 peak, the 80-ppm Rha C2 peak, and the 69-ppm GalA C2/Rha C5 peak, show modestly reduced intensities, suggesting that a small fraction of pectins may be partially immobilized at low-pH. This hypothesis is tested further using $2 \mathrm{D}{ }^{13} \mathrm{C}-{ }^{13} \mathrm{C}$ correlation and ${ }^{13} \mathrm{C}-{ }^{1} \mathrm{H}$ dipolar coupling experiments.

\section{Polysaccharide dynamics from 2D ${ }^{13} \mathrm{C}$ INADEQUATE and PDSD spectra}

To resolve the matrix polysaccharide signals, we measured $2 \mathrm{D}{ }^{13} \mathrm{C}-{ }^{13} \mathrm{C} \mathrm{J}$-INADEQUATE spectra (Fig. 2A), which correlate the sum of the chemical shifts of two directly bonded ${ }^{13} \mathrm{C}$ spins with the chemical shift of each ${ }^{13} \mathrm{C}$ spin (Cadars et al. 2007; Dick-Perez et al. 2011). Most matrix polysaccharides were observed in the 2D INADEQUATE spectra, since $1 D{ }^{13} \mathrm{C}$ DP spectra measured with a 2 s recycle delay showed $\sim 90 \%$ of the matrix polysaccharide signals compared to the quantitative spectra. Similar to previously studied primary cell walls, both the low- and high-pH spectra are dominated by pectin signals with narrow linewidths of 0.4-0.8 ppm and multiple linkages for each sugar type were resolved (Phyo et al. 2017a; Phyo et al. 2017b). We detected no significant chemical shift differences between the two cell walls except for the acidic type-a GalA, whose signals are absent in the $\mathrm{pH} 4.0$ cell wall due to neutralization.

$2 \mathrm{D}{ }^{13} \mathrm{C}-{ }^{13} \mathrm{C}$ PDSD spectra were measured using cross polarization to generate the initial ${ }^{13} \mathrm{C}$ magnetization, which complement the J-INADEQUATE spectra by preferentially detecting rigid molecules. Fig. 2B show spectra measured using a ${ }^{13} \mathrm{C}$ mixing time of $30 \mathrm{~ms}$. Similar chemical shifts and cross-peak intensities for cellulose are observed in both spectra, but many pectin cross peaks have higher intensities at low $\mathrm{pH}$ than at high $\mathrm{pH}$. Thus, the fraction of matrix polysaccharides that are selected by ${ }^{13} \mathrm{C} \mathrm{CP}$ has become more rigid at acidic $\mathrm{pH}$. The $2 \mathrm{D}$ spectra also show similar intensities for the well resolved Xyl C4-C5 cross peak at (62.5 ppm, $70.4 \mathrm{ppm})$, confirming that the amount and rigidity of $\mathrm{XyG}$ is unaffected by the $\mathrm{pH}$ change. 

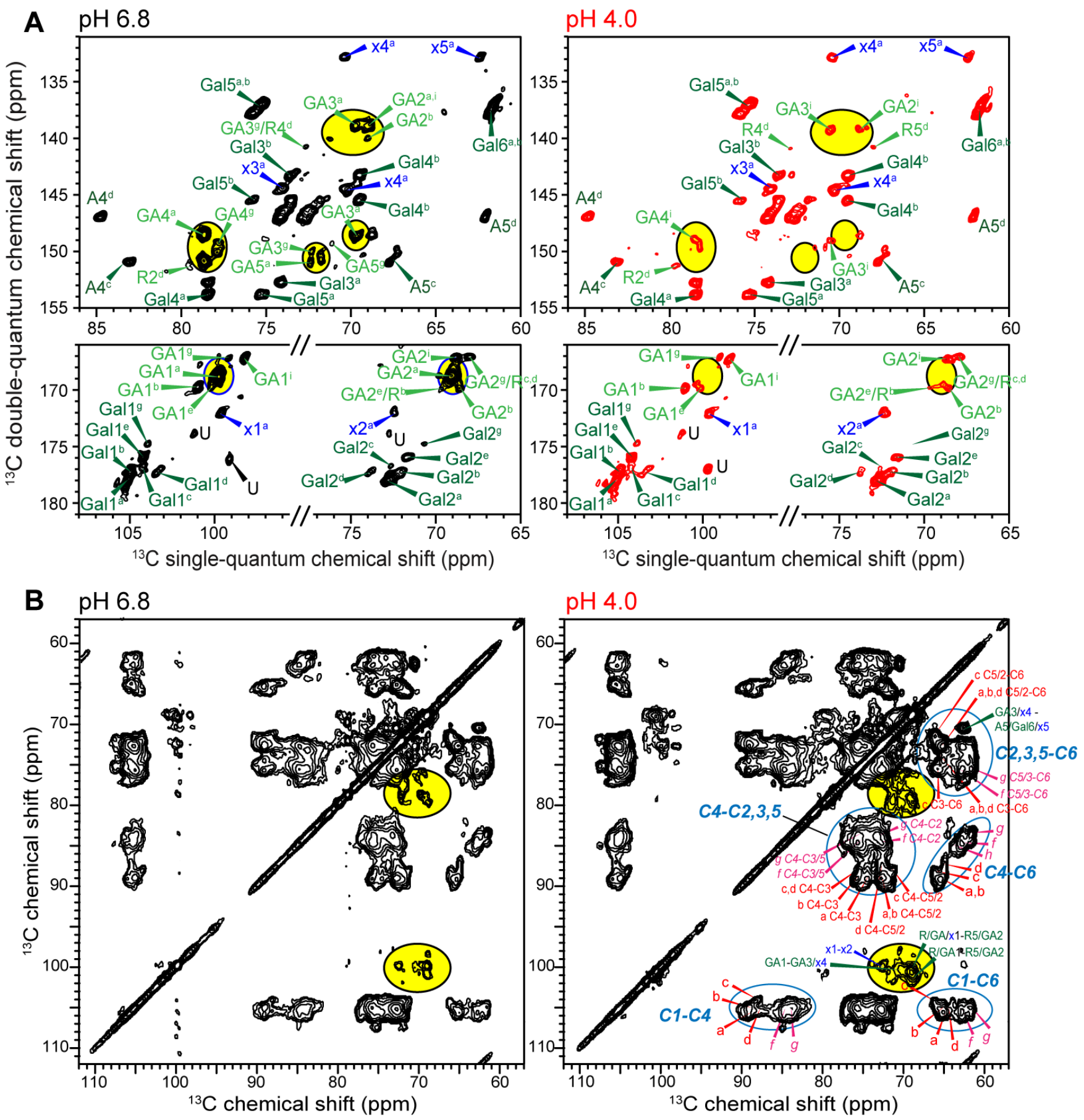

Figure 2. 2D ${ }^{13} \mathrm{C}$ DP J-INADEQUATE spectra (A) and CP-PDSD spectra (B) of pH 6.8 and $\mathrm{pH} 4.0$ cell walls. (A) Selected regions of the DP-based 2D J-INADEQUATE spectra, showing the loss of negatively charged type-a GalA signals (yellow circles) in the low-pH spectrum. (B) 2D CP-PDSD spectra with $30 \mathrm{~ms}$ mixing. The low-pH sample exhibits stronger pectin-pectin and hemicellulosehemicellulose cross peaks (yellow circles) than the high-pH sample.

\section{Polysaccharide motional amplitudes from $\mathrm{C}$-H dipolar couplings}

To obtain quantitative information about the effect of $\mathrm{pH}$ on the motional amplitudes of cell wall polysaccharides, we measured ${ }^{13} \mathrm{C}-{ }^{1} \mathrm{H}$ dipolar couplings and order parameters $\left(\mathrm{S}_{\mathrm{CH}}\right)$ using the 
DIPSHIFT experiment (Fig. 3). We conducted two versions of the experiments: the CP-based experiment selectively detects the mobility of more rigid polysaccharides, including cellulose and $\sim 40 \%$ of matrix polysaccharides (Phyo et al. 2017b), while the quantitative-DIPSHIFT experiment, measured with direct ${ }^{13} \mathrm{C}$ excitation and long recycle delays, detects the dynamics of all wall polymers. Under both $\mathrm{CP}$ and quantitative conditions, we find similar dipolar dephasing curves for cellulose and hemicellulose peaks, indicating that the mobility of these two polysaccharides are unaffected by $\mathrm{pH}$ change. In comparison, the matrix polysaccharide signals in the 100-ppm range, the $78-80 \mathrm{ppm}$ range, and at 69 ppm, show varying extents of change. The 69-ppm peak of GalA C2 and Rha C5 exhibit the largest difference, with the $\mathrm{pH} 4.0$ sample giving significantly stronger dipolar couplings, indicating increased rigidity. Stronger couplings are also observed for the Rha C2, Gal C4 and GalA C4 peaks at low pH.

A CP 2x DIPSHIFT



$\mathrm{pH} 6.8$

$\mathrm{pH} 4.0$
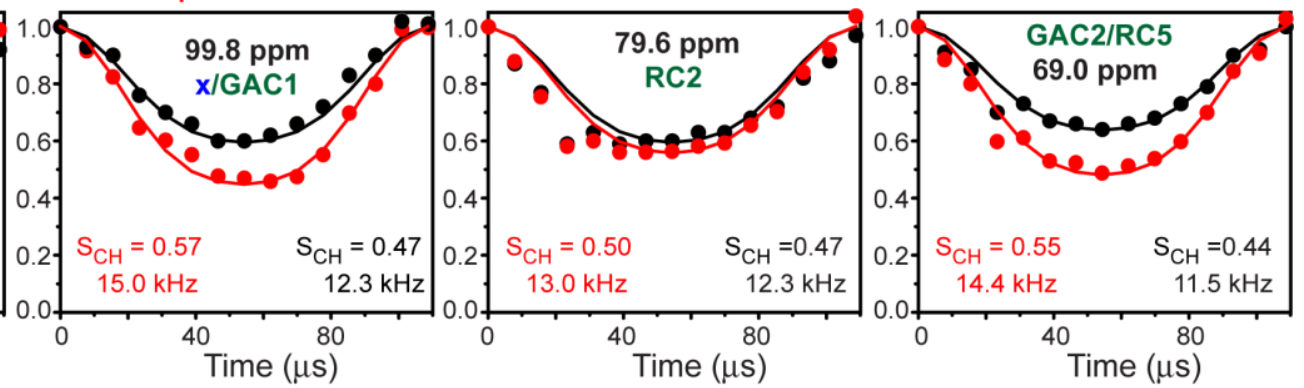

B Quantitative 1x DIPSHIFT


Figure 3. Representative ${ }^{13} \mathrm{C}-{ }^{1} \mathrm{H}$ dipolar dephasing curves of Arabidopsis primary cell walls at $\mathrm{pH} 6.8$ and $\mathrm{pH}$ 4.0. (A) CP-DIPSHIFT data, reporting the rigid fraction of wall polysaccharides. The experiment was conducted with dipolar doubling (Hong et al. 1997), a CP contact time of $500 \mu \mathrm{s}$ under $9.2 \mathrm{kHz}$ MAS at 293 K. (B) Quantitative DIPSHIFT data, reporting the dynamics of all wall polysaccharides. The data were acquired with a $20 \mathrm{~s}$ recycle delay under $7.6 \mathrm{kHz}$ MAS at $296 \mathrm{~K}$. Best-fit dipolar couplings and the corresponding order parameters $\mathrm{S}_{\mathrm{CH}}$ are given in each panel.

\section{Acidic cell wall exhibits high cellulose hydration and weaker cellulose-pectin interactions}

Previous SSNMR spectra of primary cell walls showed that calcium-crosslinked HG chains are crucial for cell wall hydration by trapping and immobilizing water (Wang et al. 2015; White et al. 2014), and polysaccharide hydration is correlated with plant growth (Phyo et al. 2017a). To investigate the effect of $\mathrm{pH}$ on the water-polysaccharides interactions, we measured water ${ }^{1} \mathrm{H}$ polarization-transferred ${ }^{13} \mathrm{C}$ spectra of the polysaccharides. The experiments were conducted at a low temperature of $253 \mathrm{~K}$ to suppress the $\mathrm{pH}$-dependent chemical exchange of hydroxyl groups (Liepinsh and Otting 1996), in order to observe the exclusive dependence of ${ }^{13} \mathrm{C}$ intensities on water accessibility of the polysaccharides. At the experimental temperature, the water ${ }^{1} \mathrm{H}$ signal of the two samples exhibits similar linewidth $(0.9$ ppm) and chemical shift (5.2 ppm), indicating similar water dynamics and hydrogen bonding (Fig. 4A). Representative ${ }^{13} \mathrm{C}$ spectra as a function of ${ }^{1} \mathrm{H}$ spin diffusion mixing time (Fig. 4B) indicate that both 
cellulose signals such as the 105-ppm and 89-ppm peaks and the matrix polysaccharide peaks build up the intensities more rapidly at low $\mathrm{pH}$ than at high $\mathrm{pH}$. Since ${ }^{1} \mathrm{H}$ spin diffusion is distance-dependent, the higher intensities indicate higher water accessibility of polysaccharides at acidic $\mathrm{pH}$. This is quantitatively manifested in the water-polysaccharides spin diffusion buildup curves (Fig. 4C). The higher water accessibility suggests that cellulose and pectins become more separated in the acidic cell wall. To verify this observation, we measured $2 \mathrm{D}{ }^{13} \mathrm{C}$ PDSD spectra using a long mixing time of $1.5 \mathrm{~s}$ (Fig. 5). Indeed, in the 101-ppm cross section of Xyl, Rha and GalA C1, which is the best-resolved matrix polysaccharide chemical shift in the 2D spectra, cross peaks with interior cellulose C4 (89 ppm) and $\mathrm{C} 6(65 \mathrm{ppm})$ have visibly lower intensities at low $\mathrm{pH}$ than at high $\mathrm{pH}$. This is also borne out by the 69-ppm cross section of GalA C2, C3, Rha C5 and Gal C4, which displays weaker cross peaks with cellulose at acidic $\mathrm{pH}$. Therefore, the acidic cell wall has weaker cellulose-pectin interactions, consistent with the enhanced hydration of the wall polymers at acidic pH. The cellulose $\mathrm{C} 6$ and $\mathrm{C} 4$ cross sections at $89 \mathrm{ppm}$ and $65 \mathrm{ppm}$ do not show significant differences in the cellulose-pectin cross peaks between the two $\mathrm{pH}$, which can be attributed to partial overlap of the interior and surface cellulose signals and the surface cellulose and matrix polysaccharides signals.
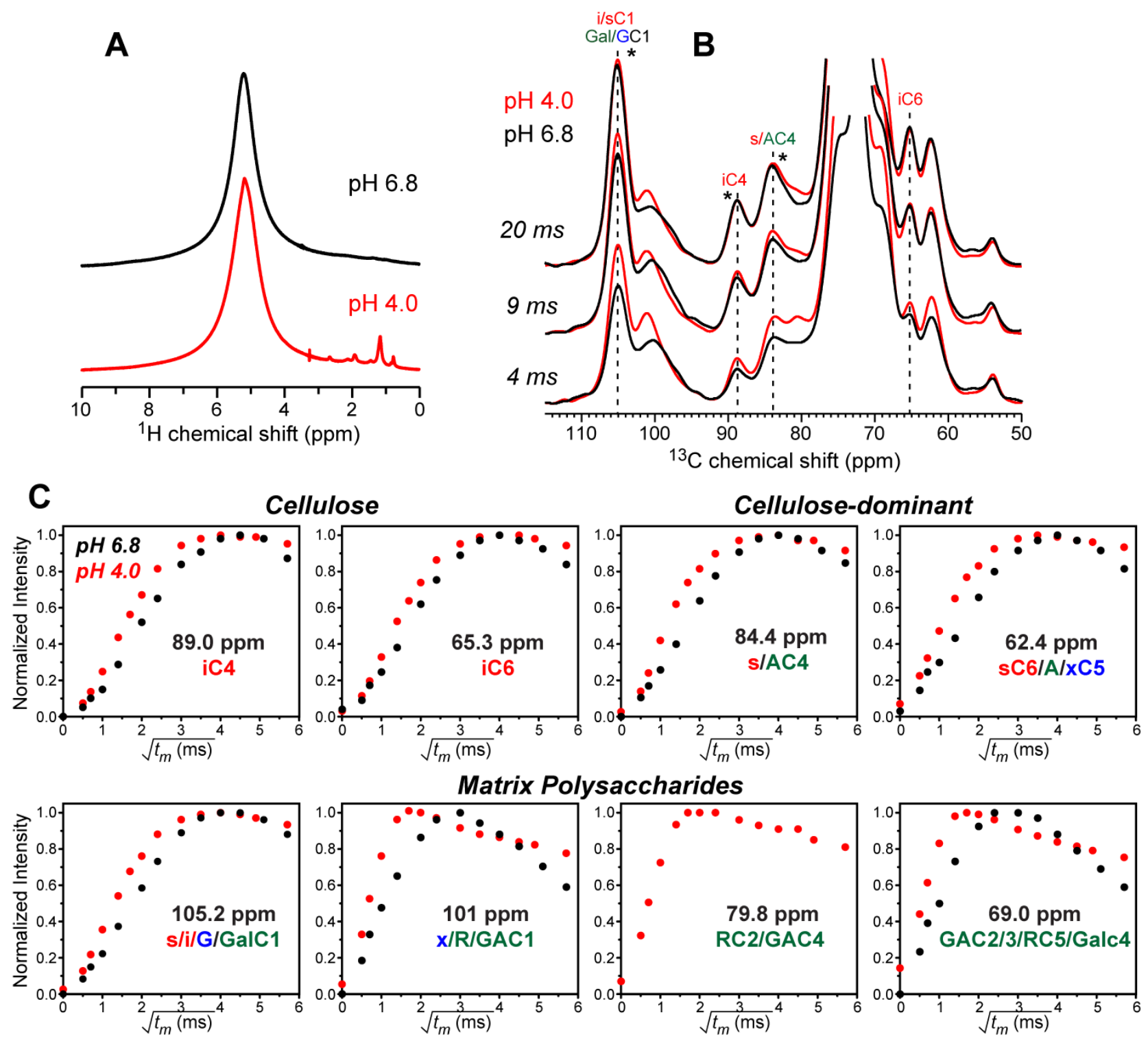
Figure 4. Water-to-polysaccharide ${ }^{1} \mathrm{H}$ spin diffusion data to probe polysaccharide hydration. The spectra were measured at $\sim 253 \mathrm{~K}$ under $10 \mathrm{kHz}$ MAS to suppress chemical exchange and allow the measurement of water accessibility. (A) ${ }^{1} \mathrm{H}$ spectra. The similar water ${ }^{1} \mathrm{H}$ linewidth and chemical shifts indicate similar water dynamics at high and low $\mathrm{pH}$. (B) Representative ${ }^{13} \mathrm{C}$ spectra after a ${ }^{1} \mathrm{H} \mathrm{T}_{2}$ filter and variable ${ }^{1} \mathrm{H}$ spin diffusion mixing times. Asterisks indicate cellulose-dominant peaks, which are normalized by their equilibrium intensities at $20 \mathrm{~ms}$. The low-pH cell wall exhibits higher pectin and cellulose signals than the high-pH sample at short mixing times, indicating better hydration. (C) Waterto-polysaccharides ${ }^{1} \mathrm{H}$ spin diffusion buildup curves, showing more rapid water magnetization transfer to polysaccharides in the $\mathrm{pH} 4.0$ cell wall.
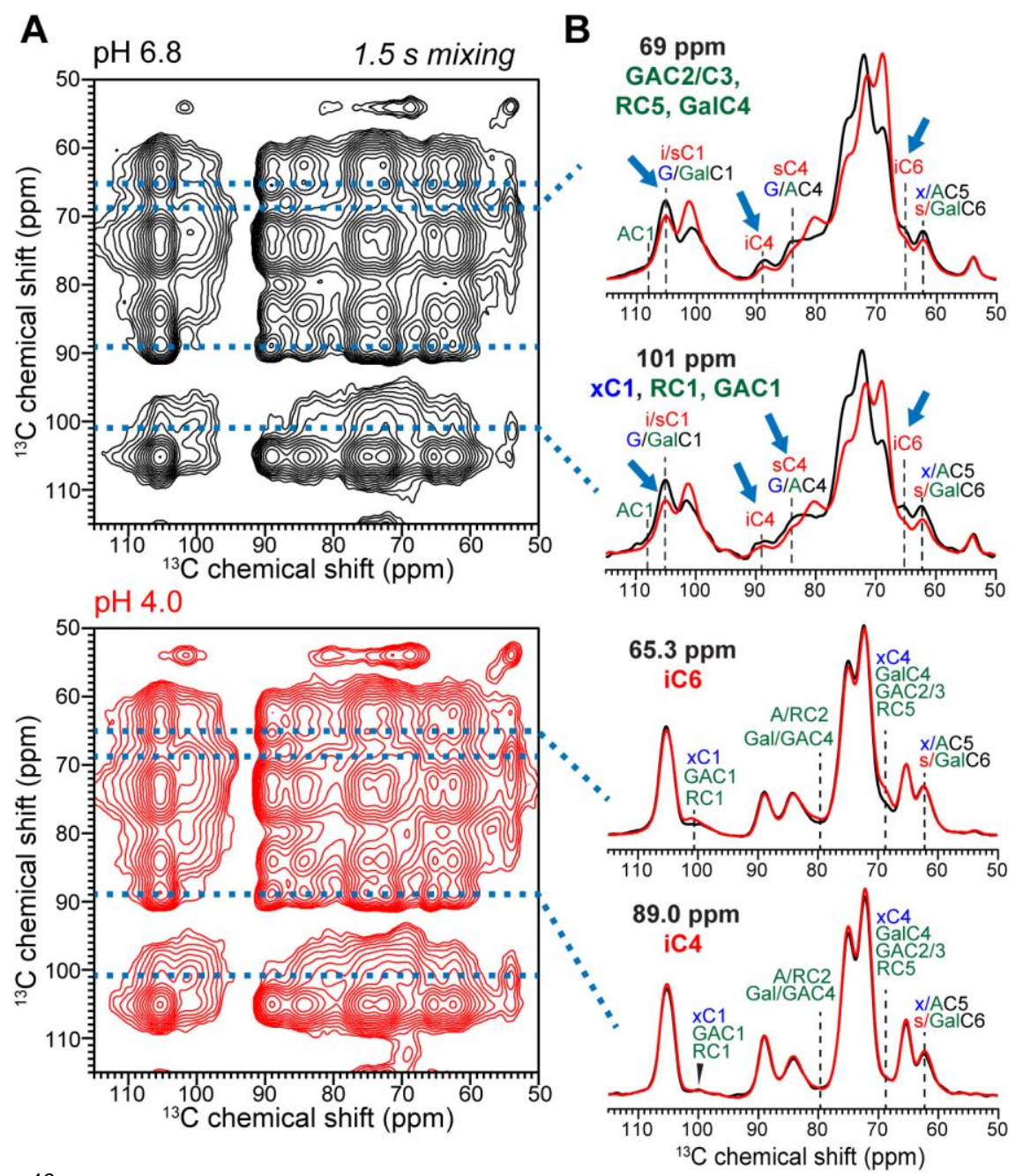

Figure 5. $1.5 \mathrm{~s} \mathrm{2D}{ }^{13} \mathrm{C}$ PDSD spectra to detect cellulose-pectin spatial contacts in cell walls at $\mathrm{pH} 6.8$ and $\mathrm{pH}$ 4.0. (A) $2 \mathrm{D}$ spectra, measured at $253 \mathrm{~K}$ under $10 \mathrm{kHz}$ MAS. (B) Key $1 \mathrm{D}{ }^{13} \mathrm{C}$ cross sections extracted from matrix polysaccharide (69 ppm and $101 \mathrm{ppm}$ ) and cellulose (65 ppm and 89 ppm) cross sections. The cross peak intensities are normalized by the integrated area of each cross section. In the 101-ppm and 69-ppm cross sections, many pectin-cellulose cross peaks have lower intensities at acidic $\mathrm{pH}$ than at neutral $\mathrm{pH}$ (arrows), indicating weaker pectin-cellulose interactions in the acidic cell wall.

\section{Discussion}

Recent solid-state NMR studies of Arabidopsis primary cell walls (Phyo et al. 2017a; Phyo et al. 2017b; Wang et al. 2015; Wang et al. 2016b) have provided extensive evidence of and insights into how pectin structure, dynamics and pectin-cellulose interactions impact cell wall mechanics and wall 
loosening. When two HG-mutant cell walls with distinct growth phenotypes were compared, the faster growing mutant displayed weaker cellulose-pectin interactions and higher methyl esterification of $\mathrm{HG}$ (Phyo et al. 2017b). In the fast growing Arabidopsis inflorescence stem, pectins are more branched, more esterified, better hydrated and more mobile than those of the slow-growing cell wall (Phyo et al. 2017a). These findings consistently indicate that pectins play a prominent role in cell wall structure and wall loosening during plant growth.

The current solid-state NMR data augment the previous studies by delineating the impact of wall acidification on the polysaccharide structure, dynamics, hydration and intermolecular interactions. Our data are acquired on primary cell walls without active enzyme actions, thus they provide information about a protein-independent mechanism of acid-induced wall loosening. We find that acidic $\mathrm{pH}$ causes neutralization of most GalA residues in HG and RG-I backbones, without changing the concentrations of other monosaccharides, methyl esters and acetyls. This is consistent with the fact that the two samples were grown under identical conditions but only differed in post-harvest processing. This simple electrostatic change of GalA residues caused a pronounced increase in the dynamic heterogeneity and the spatial separation of matrix polysaccharides in the wall. The ${ }^{13} \mathrm{C}$ INEPT spectra, 2D INADEQUATE spectra, 2D ${ }^{13} \mathrm{C}$ PDSD spectra, and C-H DIPSHIFT spectra consistently characterize at least three conformationally and dynamically distinct pectins in the acidic cell wall, while the neutral-pH cell wall has a bimodal distribution of pectin structure and dynamics. Common to both high- and low-pH cell walls are a partially immobilized population of cellulose-interacting pectins (type I) and a highly dynamic population of pectins (type II), which is located between cellulose microfibrils (Dick-Perez et al. 2011; Wang et al. 2015; Wang et al. 2016b). In addition, the acidic cell wall contains a third population of pectins, which is partially aggregated and immobilized due to charge neutralization. The type-I pectins show weaker interactions with cellulose at acidic $\mathrm{pH}$ than at neutral $\mathrm{pH}$, as manifested by the weaker pectin-cellulose cross peaks in the long-mixing-time $2 \mathrm{D}{ }^{13} \mathrm{C}-{ }^{13} \mathrm{C}$ correlation spectra and the faster water ${ }^{1} \mathrm{H}$ spin diffusion to cellulose and pectins at acidic $\mathrm{pH}$. This observation suggests that in the neutral-pH cell wall, negatively charged GalA residues enhance pectin binding to cellulose, implying the importance of electrostatic interactions for HG-cellulose interaction. The type-II, highly dynamic, interfibrillar pectins are detected in the INEPT spectra, and contain both RG-I sidechains and a subpopulation of HG chains. These type-II pectins become more dynamic at acidic $\mathrm{pH}$ than at neutral $\mathrm{pH}$, as evidenced by higher INEPT intensities. The type-III pectins are relatively rigid in the interfibrillar space, manifest cross peaks in the 30-ms 2D spectrum, and contribute intensities to the CP-DIPSHIFT data. These type-III pectins are more immobilized in the acidic cell wall, suggesting that the HG network after charge neutralization is partially aggregated, which increases the free volume between cellulose microfibrils and allows increased mobility for the other pectin chains.

Taken together, these SSNMR results indicate a more dynamically heterogeneous and structurally segregated polysaccharide network in the acidic cell wall, in which pectins are partially separated from both cellulose microfibrils and from each other (Fig. 6). At neutral pH where the cell wall extensibility is limited, the negatively charged and calcium-crosslinked HG chains establish a wellspaced pectic network between cellulose microfibrils. Our data suggest that when acidic $\mathrm{pH}$ neutralizes the GalA residues, the consequent loss of these crosslinks causes the collapse of the HG network and the aggregation of multiple pectin chains. The neutralized HG chains also partially dissociate from the cellulose microfibrils, thus increasing cellulose hydration. Finally, this pectin aggregation creates larger free volume for RG-I sidechains and other pectin backbones to undergo larger-amplitude motion. We propose that the weakened cellulose-pectin interaction and weakened pectin-pectin interactions facilitate polysaccharide slippage, thus mediating wall loosening. In the growing plant, acidic $\mathrm{pH}$ also activates polygalacturonase, pectate lyases and $\alpha$-expansin (Bosch and Hepler 2005; Cosgrove 2000), which likely unlock other key regions of the polymer network such as cellulose-hemicellulose binding sites. 

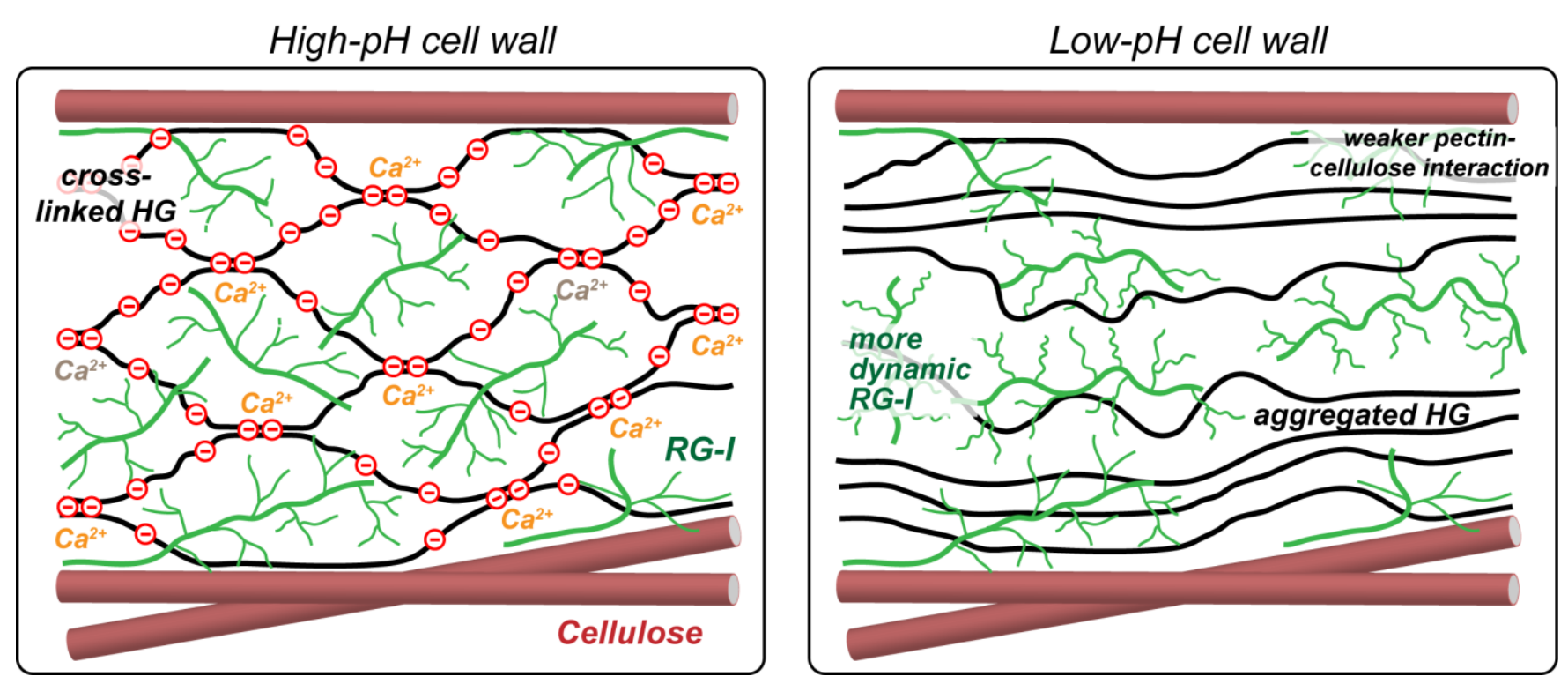

Figure 6. Structural models of acid-induced changes of cell-wall polysaccharide structure and dynamics. Cell wall acidification neutralizes GalA residues, weakens cellulose-HG interactions, causes a loss of calcium crosslinks, leads to partial aggregation of the interfibrillar HG chains, and increases the mobility of RG-I and the remaining HG. The weaker cellulose-pectin interactions and pectin-pectin interactions are proposed to cause wall loosening and expansion at acidic $\mathrm{pH}$.

\section{Conclusion}

The current solid-state NMR data provide, to our knowledge, the first molecular-level structural evidence about how acid pH changes the primary plant cell wall polysaccharide structure and dynamics to mediate wall loosening for plant growth. Acidic $\mathrm{pH}$ increases the dynamic heterogeneity and spatial separation of polysaccharides in the cell wall. Neutralization of GalA at acidic $\mathrm{pH}$ disrupts the calciumcrosslinked HG network in the interfibrillar region, causes partial aggregation and phase separation of these pectins from the highly dynamic pectins. GalA neutralization also weakens cellulose-pectin interactions and better exposes the cellulose surface to water. We propose that the disruption of both the cellulose-pectin interaction and pectin-pectin interaction contribute to the polymer slippage that underlies wall loosening at acidic $\mathrm{pH}$.

The acid-induced structural changes of wall polysaccharides observed from the present solidstate NMR data are independent of the acid activation of wall-loosening proteins such as expansin. Expansins have been recently shown to bind XyG-enriched junctions of cellulose microfibrils termed biomechanical hotspots to trigger wall loosening (Cosgrove 2016). This mechanism is determined from biomechanical, enzymatic, and NMR structural studies of XyG-deficient mutants and native cell walls (Cavalier et al. 2008; Dick-Perez et al. 2011; Park and Cosgrove 2012a; Wang et al. 2013; Xiao et al. 2016) (Park and Cosgrove 2012b). These results, together with the current study, indicate that pectins and hemicelluloses play distinct roles in wall loosening and extension. We hypothesize that the acidinduced changes in polysaccharide structures observed in this study may be similar if not identical to the protein-mediated polysaccharide structural changes at acidic $\mathrm{pH}$. Future studies will address the relation between protein-mediated acid growth and protein-independent acid growth.

\section{Acknowledgements}

This research was supported by the Center for Lignocellulose Structure and Formation, an Energy Frontier Research Center funded by the U.S. Department of Energy, Office of Science, Basic Energy Sciences under Award \# DE-SC0001090. 


\section{References}

Arsuffi G, Braybrook SA (2018) Acid growth: an ongoing trip, J Exp Bot 69:137-146

Bielecki A, Kolbert AC, Levitt MH (1989) Frequency-Switched Pulse Sequences - Homonuclear Decoupling and Dilute Spin NMR in Solids, Chem Phys Lett 155:341-346

Bosch M, Hepler PK (2005) Pectin methylesterases and pectin dynamics in pollen tubes, Plant Cell 17:3219-3226

Braybrook SA, Peaucelle A (2013) Mechano-chemical aspects of organ formation in Arabidopsis thaliana: the relationship between auxin and pectin, PLoS ONE 8:e57813

Cadars $S$ et al. (2007) The refocused INADEQUATE MAS NMR experiment in multiple spin-systems: Interpreting observed correlation peaks and optimising lineshapes, J Magn Reson 188:24-34

Cavalier DM et al. (2008) Disrupting two Arabidopsis thaliana xylosyltransferase genes results in plants deficient in xyloglucan, a major primary cell wall component, Plant Cell 20:1519-1537

Cosgrove DJ (2000) Loosening of plant cell walls by expansins, Nature 407:321-326

Cosgrove DJ (2005) Growth of the plant cell wall, Nat Rev Mol Cell Biol 6:850-861

Cosgrove DJ (2016) Catalysts of plant cell wall loosening., F1000Res 5:1-13

Cosgrove DJ (2018) Diffuse growth of plant cell walls, Plant Physiol 176:16-27

Cosgrove DJ, Bedinger P, Durachko DM (1997) Group I allergens of grass pollen as cell wall-loosening agents, Proc Natl Acad Sci USA 94:6559-6564

Dick-Perez M, Zhang YA, Hayes J, Salazar A, Zabotina OA, Hong M (2011) Structure and interactions of plant cell wall polysaccharides by two- and three-dimensional magic-angle-spinning solidstate NMR, Biochemistry 50:989-1000

Durachko DM, Cosgrove DJ (2009) Measuring plant cell wall extension (creep) induced by acidic pH and by alpha-expansin., J Vis Exp:1-4

Elena B, Lesage A, Steuernagel S, Bockmann A, Emsley L (2005) Proton to carbon-13 INEPT in solidstate NMR spectroscopy, J Am Chem Soc 127:17296-17302

Ezaki N, Kido N, Takahashi K, Katou K (2005) The role of wall Ca2+ in the regulation of wall extensibility during the acid-induced extension of soybean hypocotyl cell walls., Plant Cell Physiol 46:1831-1838

Hager A (2003) Role of the plasma membrane $\mathrm{H}_{+}-\mathrm{ATP}$ ase in auxin-induced elongation growth: historical and new aspects, J Plant Res 116:483-505

Hager A, Menzel H, Krauss A (1971) Experiments and hypothesis concerning the primary action of auxin in elongation growth, Planta 100:47-75

Hediger S, Emsley L, Fischer M (1999) Solid-state NMR characterization of hydration effects on polymer mobility in onion cell-wall material, Carbohydr Res 322:102-112 
Hong M, Gross JD, Rienstra CM, Griffin RG, Kumashiro KK, Schmidt-Rohr K (1997) Coupling amplification in 2D MAS NMR and its application to torsion angle determination in peptides, J Magn Reson 129:85-92

Kohn R, Kovac P (1978) Dissociation-constants of D-galacturonic and D-glucuronic acid and their Omethyl derivatives, Chemical Papers 32:478-485

Laskowski M, Biller S, Stanley K, Kajstura T, Prusty R (2006) Expression profiling of auxin-treated Arabidopsis roots: toward a molecular analysis of lateral root emergence, Plant Cell Physiol 47:788-792

Lesage A, Auger C, Caldarelli S, Emsley L (1997) Determination of through-bond carbon-carbon connectivities in solid-state NMR using the INADEQUATE experiment, J Am Chem Soc 119:7867-7868

Liepinsh E, Otting G (1996) Proton exchange rates from amino acid side chains--implications for image contrast, Magn Reson Med 35:30-42

Lüthen H, Bigdon M, Böttger M (1990) Reexamination of the Acid growth theory of auxin action, Plant Physiol 93:931-939

Majda M, Robert S (2018) The role of auxin in cell wall expansion, Int J Mol Sci 19:1-21

Mcqueen-mason SJ, Cosgrove DJ (1995) Expansin Mode of Action on Cell-Walls - Analysis of Wall Hydrolysis, Stress-Relaxation, and Binding, Plant Physiol 107:87-100

Munowitz MG, Griffin RG, Bodenhausen G, Huang TH (1981) Two-Dimensional Rotational Spin-Echo Nuclear Magnetic-Resonance in Solids - Correlation of Chemical-Shift and Dipolar Interactions, J Am Chem Soc 103:2529-2533

Park YB, Cosgrove DJ (2012a) Changes in cell wall biomechanical properties in the xyloglucandeficient xxt1/xxt2 mutant of arabidopsis, Plant Physiol 158:465-475

Park YB, Cosgrove DJ (2012b) A revised architecture of primary cell walls based on biomechanical changes induced by substrate-specific endoglucanases, Plant Physiol 158:1933-1943

Phyo P, Wang T, Kiemle SN, O'Neill H, Pingali SV, Hong M, Cosgrove DJ (2017a) Gradients in wall mechanics and polysaccharides along growing inflorescence stems, Plant Physiol 175:15931607

Phyo P, Wang T, Xiao C, Anderson CT, Hong M (2017b) Effects of pectin molecular weight changes on the structure, dynamics, and polysaccharide interactions of primary cell walls of Arabidopsis thaliana: insights from solid-state NMR, Biomacromolecules 18:2937-2950

Prat R, Gueissaz MB, Goldberg R (1984) Effects of Ca-2+ and Mg-2+ on elongation and H+ secretion of vigna radiata hypocotyl sections., Plant Cell Physiol 25:1459-1467

Rienstra CM et al. (2002) De novo determination of peptide structure with solid-state magic-angle spinning NMR spectroscopy, Proc Natl Acad Sci USA 99:10260-10265 
Tepfer M, Cleland RE (1979) A comparison of acid-induced cell wall loosening in valonia ventricosa and in oat coleoptiles., Plant Physiol 63:898-902

Wang T, Chen Y, Tabuchi A, Hong M, Cosgrove DJ (2016a) The Target of beta-Expansin EXPB1 in Maize Cell Walls from Binding and Solid-State NMR Studies, Plant Physiol

Wang T, Hong M (2016) Solid-state NMR investigations of cellulose structure and interactions with matrix polysaccharides in plant primary cell walls, J Exp Bot 67:503-514

Wang T, Park YB, Caporini MA, Rosay M, Zhong LH, Cosgrove DJ, Hong M (2013) Sensitivityenhanced solid-state NMR detection of expansin's target in plant cell walls, Proc Natl Acad Sci USA 110:16444-16449

Wang T, Park YB, Cosgrove DJ, Hong M (2015) Cellulose-pectin spatial contacts are inherent to neverdried Arabidopsis thaliana primary cell walls: evidence from solid-state NMR, Plant Physiol 168:871-883

Wang T, Phyo P, Hong M (2016b) Multidimensional solid-state NMR spectroscopy of plant cell walls, Solid State Nucl Magn Reson 78:56-63

Wang T, Salazar A, Zabotina OA, Hong M (2014) Structure and dynamics of Brachypodium primary cell wall polysaccharides from two-dimensional ${ }^{13} \mathrm{C}$ solid-state nuclear magnetic resonance spectroscopy, Biochemistry 53:2840-2854

Wang T, Zabotina O, Hong M (2012) Pectin-cellulose interactions in the Arabidopsis primary cell wall from two-dimensional magic-angle-spinning solid-state nuclear magnetic resonance, Biochemistry 51:9846-9856

White PB, Wang T, Park YB, Cosgrove DJ, Hong M (2014) Water-polysaccharide interactions in the primary cell wall of Arabidopsis thaliana from polarization transfer solid-state NMR, J Am Chem Soc 136:10399-10409

Xiao C, Zhang T, Zheng Y, Cosgrove DJ, Anderson CT (2016) Xyloglucan deficiency disrupts microtubule stability and cellulose biosynthesis in Arabidopsis, altering cell growth and morphogenesis, Plant Physiol 170:234-249

Yu B, van Ingen H, Vivekanandan S, Rademacher C, Norris SE, Freedberg DI (2012) More accurate $1 \mathrm{~J}(\mathrm{CH})$ coupling measurement in the presence of $3 \mathrm{~J}(\mathrm{HH})$ strong coupling in natural abundance, J Magn Reson 215:10-22 


\section{Graphical abstract}



